\title{
ANALISIS SALURAN PEMASARAN COMRING (Studi Kasus pada UKM Surya di Desa Kertayasa Kecamatan Panawangan Kabupaten Ciamis)
}

\author{
HEDI NUR HIDAYAT ${ }^{*}$, TRISNA INSAN NOOR ${ }^{2}$, BUDI SETIA $^{1}$ \\ ${ }^{1}$ Fakultas Pertanian, Universitas Galuh \\ ${ }^{2}$ Fakultas Pertanian, Universitas Padjadjaran
}

\begin{abstract}
ABSTRAK
Penelitian ini bertujuan untuk mengetahui: saluran pemasaran, biaya pemasaran, marjin dan keuntungan pemasaran serta producer's share comring pada UKM Surya di Desa Kertayasa Kecamatan Panawangan Kabupaten Ciamis. Metode penelitian yang digunakan adalah studi kasus. Data yang diperoleh terdiri atas data primer dan data sekunder. Jumlah informan sebanyak 13 orang, satu orang produsen, dua orang pedagang pengumpul dan sepuluh orang pedagang pengecer. Hasil penelitian adalah:

1. Terdapat dua saluran pemasaran yaitu:

Saluran I : Produsen $\rightarrow$ Pedagang Pengumpul $\rightarrow$ Pedagang Pengecer $\rightarrow$ Konsumen Akhir

Saluran II : Produsen $\rightarrow$ Pedagang Pengecer $\rightarrow$ Konsumen Akhir

2. Pada Saluran I besarnya rata-rata marjin pemasaran Rp 13.000,00 per kilogram, rata-rata biaya pemasaran Rp 485,73 per kilogram, rata-rata keuntungan pemasaran Rp 12.514,27 per kilogram. Pada Saluran II besarnya rata-rata marjin pemasaran Rp 16.000,00 per kilogram, rata-rata biaya pemasaran Rp 133,20 per kilogram, rata-rata keuntungan pemasaran Rp 15.866,80 per kilogram.

3. Producer's share Saluran I adalah 59,37 persen dan Saluran II adalah 54,28 persen.

4. Saluran I nilai efisiensi pemasarannya adalah 1.52 persen dan Saluran II adalah 0,38 persen.
\end{abstract}

Kata Kunci : Saluran, Pemasaran, Comring

\section{PENDAHULUAN}

Pembangunan pertanian di

Indonesia tetap dianggap terpenting dari keseluruhan pembangunan ekonomi, apalagi pada saat sektor pertanian ini menjadi penyelamat perekonomian nasional terbukti ketika krisis multidimensi pada tahun 1998, pertanian menunjukkan peningkatan sementara sektor lain pertumbuhannya negatif. Pertanian merupakan sektor primer yang mempunyai peranan strategis dalam struktur pengembangan pembangunan pertanian karena usaha agribisnis memiliki prospek yang cerah untuk dikembangkan oleh pelaku usaha agribisnis (Muawin, 2010 dalam Sholihah, 2014).

Agroindustri dapat menjadi salah satu alternatif untuk meningkatkan perekonomian masyarakat, mengurangi pengangguran dan memperbaiki pembagian pendapatan. Agroindustri merupakan industri yang mengolah bahan baku hasil pertanian menjadi barang yang mempunyai nilai tambah yang dapat dikonsumsi oleh masyarakat. Berbeda dengan industri lain, bahan baku agroindustri telah banyak tersedia di dalam negeri, dengan kata lain bahan baku agroindustri tidak tergantung pada impor 
dari negara lain. Dengan mengembangkan agroindustri secara tidak langsung dapat membantu meningkatkan perekonomian para petani sebagai penyedia bahan baku untuk industri (Todaro. 1994, dalam Imran 2014).

Salah satu komoditi unggulan yang merupakan salah satu kebutuhan bahan pangan adalah singkong. Keunggulan singkong sebagai bahan pangan pokok sudah diketahui sejak zaman dahulu. Singkong dapat dimakan dalam berbagai bentuk masakan. Di Indonesia singkong dimakan setelah dikukus, dibakar, digoreng dan diolah menjadi berbagai macam panganan atau diragikan menjadi tempe. Dari gaplek dapat dibuat tiwul, gatot dan berbagai macam masakan lainnya (Islami, 2014).

Salah satu agroindustri yang potensial dikembangkan di Kabupaten Ciamis yaitu agroindustri keripik ubi kayu, khususnya agroindustri comring. Salah satu sentra agroindustri comring di Kabupaten Ciamis yang bertempat di Desa Kertayasa Kecamatan Panawangan yaitu UKM Surya. Nama "Surya" tersebut merupakan nama perusahaan itu sendiri sekaligus nama label produksi.

Comring atau comro kering adalah makanan ringan yang terbuat dari ubi kayu, selain itu cara pembuatan comring cukup mudah. Comring merupakan makanan ringan yang sudah tidak asing lagi di kalangan masyarakat. Hal ini dapat kita lihat dengan semakin banyaknya usaha kecil menengah yang memproduksi comring, apabila ditinjau dari aspek ekonomis usaha pembuatan comring mempunyai prospek yang menggembirakan, karena dengan harga yang terjangkau konsumen bisa menikmati makanan ringan comring.

Identifikasi yang dilakukan dalam penelitian ini adalah melihat saluran pemasaran yang terdapat pada UKM Comring Surya milik bapak Bento di Desa Kertayasa Kecamatan Panawangan Kabupaten Ciamis untuk mengetahui bagian harga yang diterima produsen. Hasil dari identifikasi akan digunakan untuk mengelola masalah-masalah yang terjadi di perajin comring.

\section{METODE PENELITIAN}

\section{Metode dan Jenis Penelitian}

Metode penelitian yang digunakan adalah penelitian kualitatif. Jenis penelitian yang digunakan adalah studi kasus pada Perusahaan Surya di Desa Kertayasa Kecamatan Panawangan Kabupaten Ciamis. 


\section{Sumber dan Teknik Pengumpulan Data}

Sumber data yang digunakan terdiri atas data primer dan data sekunder. Teknik pengumpulan data yaitu wawancara, observasi dan studi literatur.

\section{Teknik Penarikan Sampel}

Teknik penarikan sampel dilakukan secara sengaja (purposive sampling) yaitu pada perusahaan Surya di Desa Kertayasa Kecamatan Panawangan Kabupaten Ciamis dengan pertimbangan bahwa perusahaan tersebut merupakan perusahaan dengan produksi tinggi. Menurut Zulganef (2018) purposive sampling yaitu metode untuk memperoleh informasi dari sasaransasaran sampel tertentu yang disengaja oleh peneliti, karena hanya sampel tersebut saja yang mewakili.

Teknik penarikan sampel lembaga pemasaran dilakukan dengan cara Snow Ball Sampling. Zulganef (2018) menyatakan bahwa Snow Ball Sampling adalah metode pengambilan sampel melalui sekelompok informan awal, selanjutnya responden awal tersebut diminta untuk mengidentifikasi informan lain yang memiliki karakteristik sesuai dengan target populasi untuk pengambilan sampel.

\section{Rancangan Analisis Data}

1. Mengetahui saluran pemasaran comring digunakan analisis deskriptif kualitatif.

2. Untuk mengetahui marjin pemasaran menggunakan rumus menurut (Angipora, 2002) sebagai berikut:

$$
\mathrm{Mm}=\mathrm{Pe}-\mathrm{Pf}
$$

Dimana,

$\mathrm{Mm}=$ Marjin pemasaran ditingkat produsen

$\mathrm{Pe}=$ Harga produk ditingkat lembaga pemasaran $(\mathrm{Rp} / \mathrm{kg})$

Pf = Harga produk ditingkat produsen $(\mathrm{Rp} / \mathrm{kg})$

3. Karena dalam marjin pemasaran terdapat dua komponen yaitu komponen biaya dan komponen keuntungan maka:

$$
\begin{aligned}
& \mathrm{Mm}=\pi+\mathrm{TC} \\
& \pi=\mathrm{Mm}-\mathrm{TC}
\end{aligned}
$$

Dimana,

$\mathrm{Mm}=$ Marjin pemasaran di tingkat produsen

$\pi=$ Keuntungan di tingkat lembaga pemasaran

$\mathrm{TC}=$ Total Cost (total biaya pemasaran di tingkat lembaga pemasaran)

4. Untuk mengetahui bagian harga yang diterima produsen (Producer's Share) 
menggunakan rumus (Angipora, 2002):

$$
P S=\frac{P f}{P e} \times 100 \%
$$

Dimana,

PS = Bagian harga yang diterima produsen (Producer's Share)

Pf = Harga di tingkat produsen $(\mathrm{Rp} / \mathrm{kg})$

$\mathrm{Pe}=$ Harga di tingkat pengecer $(\mathrm{Rp} / \mathrm{kg})$

5. Menurut Rosmawati (2011) efisiensi atau tidaknya pemasaran dapat dilihat dari seberapa besarnya nilai EP (Efisiensi Pemasaran) dalam saluran pemasaran tersebut.

$$
\begin{aligned}
& \mathrm{EP}=0-33 \% \quad \rightarrow \text { Efisien } \\
& \mathrm{EP}=34-67 \% \rightarrow \text { Kurang Efisien } \\
& \mathrm{EP}=68-100 \% \rightarrow \text { Tidak Efisien }
\end{aligned}
$$

Menurut Soekartawi (2002) untuk menghitung efisiensi pemasaran dapat digunakan rumus sebagai berikut:

$$
\mathrm{EP}=\frac{\mathrm{BP}}{\mathrm{NP}} \times 100 \%
$$

Dimana:

$\mathrm{EP}=$ Efisiensi pemasaran $(\%)$

$\mathrm{BP}=$ Total biaya pemasaran $(\mathrm{Rp} / \mathrm{kg})$

$\mathrm{NP}=$ Total nilai produk yang dijual $(\mathrm{Rp} / \mathrm{kg})$

\section{Tempat dan Waktu Penelitian}

Penelitian ini telah dilaksanakan pada UKM Surya di Desa Kertayasa
Kecamatan Panawangan Kabupaten Ciamis pada bulan Maret sampai bulan Juli 2019.

\section{HASIL DAN PEMBAHASAN}

Profil dan Ruang Lingkup

Nama Perusahaan : Surya

Nama Pemilik : Dedi Supriadi

Alamat : Desa Kertayasa,

Kecamatan

Panawangan,

Ciamis

Telepon : 0852-7255-****

Tahun Didirikan : 2005

Bentuk Usaha : Perseorangan

\section{Saluran Pemasaran Comring}

Pemasaran comring di Desa Kertayasa Kecamatan Panawangan Kabupaten Ciamis melalui dua saluran pemasaran, dimana pelaku pemasaran yang terlibat dalam saluran pemasaran dari produsen ke konsumen adalah pedagang pengumpul dan pedagang pengecer.

Saluran pemasaran comring yang terletak di Desa Kertayasa ini melalui beberapa lembaga pemasaran diantaranya pedagang pengumpul dan pedagang pengecer. Comring ini dipasarkan dalam satuan rupiah per kilogram. Untuk memperluas dan memperlancar pemasaran comring sangat dibutuhkan peran lembaga 
pemasaran untuk menyalurkan comring dari produsen hingga ke konsumen. Dengan adanya tingkat saluran pemasaran akan menyebabkan tingkat marjin, biaya dan keuntungan yang berbeda, pembagian keuntungan yang adil antara pelaku pemasaran hanya ditentukan oleh efisiensi pemasaran.

Pengusaha dalam pemasaran comring berperan sebagai produsen dan merupakan pihak pertama dalam penyaluran comring. Proses penyaluran hasil produksi merupakan bagian yang tidak terpisahkan setelah produksi barang oleh indutri perusahaan.

Proses awal pemasaran comring dimulai dari produsen mengantarkan pada pedagang yang terletak di Baregbeg dengan jumlah 75 kilogram dan dengan harga beli Rp 19.000,00 per kilogram, serta untuk biaya pengangkutan sebesar Rp 5.000,00. Sistem pembayaran yang dilakukan adalah cash. Lalu produsen melanjutkan kembali mengantarkan comring pada pengumpul yang terletak di Tasikmalaya dengan jumlah 425 kilogram dan dengan harga beli Rp 19.000,00 per kilogram, serta biaya pengangkutan sebesar Rp 35.000,00. Sistem pembayaran yang dilakukan adalah cash.

\section{Marjin Pemasaran Comring}

Marjin pemasaran comring pada masing-masing lembaga pemasaran adalah perbedaan harga jual dengan harga beli di masing-masing lembaga pemasaran. Pada Saluran I pedagang pengumpul membeli produk dengan harga beli sebesar Rp 19.000,00 per kilogram dan harga jual sebesar Rp 25.000,00 per kilogram. Sedangkan pedagang pengecer membeli dengan harga Rp 25.000,00 per kilogram dan harga jual sebesar Rp 32.000,00 per kilogram. Dan pada Saluran II pedagang pengecer membeli produk dengan harga beli Rp 19.000,00 per kilogram dan harga jual Rp 35.000,00 per kilogram.

Sehingga dapat diketahui rata-rata marjin pemasaran pada Saluran I sebesar Rp 13.000,00 per kilogram dan pada Saluran II sebesar Rp 16.000,00 per kilogram.

\section{Biaya dan Keuntungan Pemasaran Comring}

Biaya pemasaran comring adalah biaya yang dikeluarkan dalam proses penyaluran barang dari produsen ke konsumen akhir. Keuntungan pemasaran comring pada UKM Surya di Desa Kertayasa pada Saluran I sebesar Rp 12.514,27 per kilogram, yang didapat dari marjin pemasaran sebesar Rp 13.000,00 
per kilogram dikurangi dengan total biaya yang dikeluarkan sebesar Rp 485,73 per kilogram. Dan keuntungan pemasaran pada Saluran II sebesar $\operatorname{Rp} 15.866,80$ per kilogram, yang didapat dari marjin pemasaran sebesar Rp 16.000,00 per kilogram dikurangi dengan total biaya yang dikeluarkan sebesar Rp 133,20 per kilogram.

\section{Producer's Share Pemasaran Comring}

Berdasarkan hasil penelitian diketahui bahwa harga jual comring di produsen adalah $\mathrm{Rp} 19.000,00$ per kilogram, pada Saluran I di pedagang pengumpul adalah $\operatorname{Rp} 25.000,00$ per kilogram dan di pedagang pengecer adalah Rp 32.000,00 per kilogram, dan pada saluran II di pedagang pengecer adalah $\mathrm{Rp}$ 35.000,00 per kilogram.

Maka besarnya nilai Producer's Share comring pada Saluran I adalah:

$$
\begin{gathered}
\text { Producer's Share }=\frac{\mathrm{Pf}}{\mathrm{Pe}} \times 100 \% \\
=\frac{19.000,00}{\begin{array}{c}
32.000,00 \\
=59,37 \%
\end{array}} \times 100 \%
\end{gathered}
$$

Dan nilai Producer's Share comring pada Saluran II adalah:

$$
\begin{aligned}
& \text { Producer's Share }=\frac{\mathrm{Pf}}{\mathrm{Pe}} \times 100 \% \\
& \begin{array}{l}
=\frac{19.000,00}{35.000,00} \times 100 \% \\
=54,28 \%
\end{array}
\end{aligned}
$$

Hasil perhitungan menunjukkan bahwa nilai Producer's Share pada Saluran I lebih tinggi yaitu 59,37 persen daripada Saluran II yaitu 54,28 persen. Artinya besarnya producer's share pada Saluran I lebih tinggi daripada Saluran II dari harga yang dibayarkan konsumen.

\section{Efisiensi Pemasaran Comring}

Sistem pemasaran dianggap efisien apabila mampu menyampaikan hasil-hasil dari produsen kepada konsumen dengan biaya wajar serta mampu mengadakan pembagian yang adil dari keseluruhan harga yang dibayarkan konsumen.

Besarnya nilai efisiensi pemasaran comring pada Saluran I adalah:

$$
\begin{aligned}
\mathrm{EP} & =\frac{\mathrm{BP}}{\mathrm{NP}} \times 100 \% \\
& =\frac{485,73}{32.000,00} \times 100 \% \\
& =\begin{array}{l}
1,52 \% \\
\text { nilai Producer's Share }
\end{array}
\end{aligned}
$$
comring pada Saluran II adalah:

$$
\begin{aligned}
\mathrm{EP} & =\frac{\mathrm{BP}}{\mathrm{NP}} \times 100 \% \\
& =\frac{133,20}{35.000,00} \times 100 \% \\
& =0,38 \%
\end{aligned}
$$

Hasil perhitungan menunjukkan bahwa Saluran II lebih efisien dibandingkan Saluran I karena nilai efisiensinya lebih kecil. Hasil penelitian ini juga tidak ada kesenjangan dengan teori yang dikemukakan oleh para ahli yang menyebutkan bahwa saluran pemasaran 
dikatakan efisien apabila nilai efisiensi pemasarannya tidak melebihi dari 33 persen.

\section{KESIMPULAN DAN SARAN}

\section{Kesimpulan}

Berdasarkan hasil pembahasan, maka kesimpulannya sebagai berikut:

1. Terdapat dua saluran pemasaran comring sampai ke konsumen yaitu:

Saluran I : Produsen $\rightarrow$ Pedagang Pengumpul $\rightarrow$ Pedagang Pengecer $\rightarrow$ Konsumen Akhir

Saluran II : Produsen $\rightarrow$ Pedagang Pengecer $\rightarrow$ Konsumen Akhir

2. Pada Saluran I melibatkan dua lembaga pemasaran yaitu pedagang pengempul dan pedagang pengecer sedangkan pada Saluran II melibatkan satu lembaga pemasaran yaitu pedagang pengecer. Pada Saluran I besarnya rata-rata marjin pemasaran adalah Rp 13.000,00 per kilogram dengan rata-rata biaya pemasaran sebesar Rp 485,73 per kilogram sehingga rata-rata keuntungan pemasaran sebesar Rp 12.514,27 per kilogram. Sedangkan pada Saluran II besarnya rata-rata marjin pemasaran adalah Rp 16.000,00 per kilogram dengan rata-rata biaya pemasaran sebesar $\operatorname{Rp} 133,20$ per kilogram sehingga rata-rata keuntungan pemasaran sebesar Rp 15.866,80 per kilogram. Biaya pada Saluran I lebih banyak yaitu Rp 485,73,00 per kilogram dibandingkan Saluran II yaitu $\operatorname{Rp~133,20~per~kilogram~karena~}$ pada Saluran I lebih banyak lembaga pemasarannya.

3. Besarnya producer's share pada Saluran I adalah 59,37 persen dan pada Saluran II adalah 54,28. Artinya producer's share pada Saluran I lebih tinggi daripada Saluran II dari harga yang dibayarkan konsumen.

4. Pada Saluran I nilai efisiensi pemasarannya sebesar 1.52 persen dan pada Saluran II nilai efisiensi pemasarannya sebesar 0,38 persen. Sehingga kedua saluran pemasaran tersebut dikatakan efisien karena nilai efisiensi pemasarannya tidak melebihi dari 33 persen.

\section{Saran}

Berdasarkan kesimpulan, maka dapat disarankan hal-hal sebagai berikut:

1. Produsen harus kreatif dalam menginovasi rasa untuk produk comring, supaya produk yang 
dihasilkan dapat menarik perhatian konsumen yang lebih luas.

2. Baik produsen maupun lembaga pemasaran yang terlibat harus lebih aktif lagi dalam mencari informasi pasar, supaya bisa menjadi bahan referensi dalam memasarkan produk comring dan meningkatkan pendapatan, yaitu dengan cara menggunakan internet (online), supermarket, dll.

\section{DAFTAR PUSTAKA}

Angipora. 2002. Dasar-dasar Pemasaran, Edisi Kedua. Raja Grafindo Persada. Jakarta.

Imran. 2014. Analisis Nilai Tambah Keripik Ubi Kayu di UMKM Barokah.
Jurnal Perspektif Pembiayaan dan Pembangunan Daerah Vol. 1 No. 4.

Islami, T. 2014. Singkong: Tinjauan Aspek Ekofisiologi Serta Upaya Peningkatan dan Keberlanjutan Hasil Tanaman. Graha Ilmu. Malang.

Rosmawati, H. 2011. Analisis Efisiensi Pemasaran Pisang Produksi Petani di Kecamatan Lengkiti Kabupaten Organ Komering Ulu. Jurnal Agromobis. Vol 3(5).

Sholihah, H., Imam Hidayat, S., Yuliati, N. 2014. Persepsi dan Sikap Nasabah dalam Memperoleh Kredit Usaha Agribisnis pada Bank Konvensional dan Bank Syariah. JSEP Vol. 7 No. 1 Juli 2014: 1-8.

Soekartawi. 2005. "Agribisnis: Teor dan Aplikasinya”. Rajawali Pers. Jakarta.

Zulganef. 2018. Metode Penelitian Bisnis dan Manajemen. PT Refika Aditama. Bandung. 